\title{
Impact of Deforestation on Climate Change
}

\author{
Mrs. Archana K. \\ Assistant Professor in Law, KSLU's Law School, Hubli, Karnataka
}

\begin{abstract}
Ever since their evolution, forests have been interacting with the Earth's climate. Deforestation and forest degradation in many countries has lead to forest fragmentation with effects on increasingly insularized and vulnerable forest habitat patches. If forest fragments are becoming too small to support important keystone species, further extinctions may occur in cascading ways and the vegetation structure and composition may eventually collapse. Until now relatively few reported cases of species extinctions can be directly attributed to climate change. However, climate change in combination with habitat destruction, degradation, and fragmentation may lead to new waves of species extinctions in the near future as species are set on the move but are unable to reach cooler refuges due to altered, obstructing landscapes. To mitigate the future risks of extinctions as well as climate change, major efforts should be undertaken to protect intact large areas of forests and restore wildlife corridors.
\end{abstract}

Key Words: Clean Development Mechanism, Climate change, Deforestation, Emission testing, Green House Gas, Kyoto Protocol, and Rio Declaration/UNFCCC

\section{Introduction}

For many decades our societies have pursued the objectives of economic growth and material progress. These objectives were partly met in that one can today expect a longer life, higher incomes, more leisure time, etc. On the other hand, adverse effects have also been generated, the consequences of which one today has to pay for dearly. Environmental problems, affected quality of living in some respect and the rise of inequalities are some of the numerous reasons why economic growth does not any longer positively impact on life satisfaction. Man's greed attacks nature environment and ecology and wounded nature backlashes on the human future.

In recent years deforestation has risen to dangerous levels. Deforestation is the clearing the land of forest or trees. Many people do not even know that this problem exists, although it may be occurring right in their own neighbourhoods. The effects of deforestation on the environment are numerous. The reduction of forests upsets the entire ecological cycle. The forests are home to a number of plants and animals. When a forest is cut down, the whole cycle suffers because; the forests act as a carbon "sink". That is they help to take in carbon, a green house gas, and offset its effect on the atmosphere. Also trees and plants on a forest can help to supply an alternative source of fossil fuels.

There is overwhelming evidence and consensus that deforestation is one of the major cause for climate change. In fact, the impacts of climate change are occurring faster than what many scientists first predicted. An estimated 75 to $80 \%$ of global emissions stem from industrial sources, specifically, the burning of fossil fuels. The remaining 20 to $25 \%$ can be sourced to deforestation emissions, predominantly in the tropics. Both, the burning of fossil fuels and deforestation, must be urgently and effectively addressed in order to save the world's biodiversity and people from catastrophic climate change. At this time, a new opportunity exists to address the issue of deforestation within the climate change regime ${ }^{1}$.

The purpose of this paper is to raise critical issues on the relationship between climate change and deforestation. It analyses current policy approaches including, that reflected in the Kyoto Protocol, on the grounds that they have inadvertently resulted in the placing of climate policy and development into separate boxes.

\section{The Importance Of Forests}

Forests purify our air, preserve watersheds and improve water quality and quantity, stabilize soil and prevent erosion, provide us with natural resources such as timber products and medicinal plants, and are home to many of the world's most endangered wildlife species. In addition, an estimated 1.6 billion people worldwide rely on forests for their livelihoods, with 60 million indigenous people depending on forests for their subsistence. Another critically important function of forests increasingly and widely acknowledged now is that they help to protect the planet from climate change by absorbing carbon dioxide $(\mathrm{CO} 2)$, a major greenhouse gas.

\footnotetext{
${ }^{1}$ IPCC, 1996, "Climate Change 1995. Impacts, Adaptation, and Mitigation of Climate Change: Scientific-Technical Analyses", Watson, R.T., Zinyowera, M.C., and Moss, R.H., (eds), Contribution of Working Group II to the Second Assessment of the Intergovernmental Panel on Climate Change, Cambridge: Cambridge University Press.
} 
It is now widely recognized that rising concentration of so-called greenhouse gases (GHGs) are driving changes in the Earth's climate patterns, resulting in catastrophic weather events, such as hurricanes, heat waves, droughts and floods, and threatening plant and animal life. Forests play a critical role in protecting the Earth from climate change and regulating climate patterns, as the trees - trunks, branches and roots - and even soil absorb and store $\mathrm{CO} 2$, providing a natural reservoir for this $\mathrm{GHG}^{2}$.

In fact, the Earth's vegetation and soils currently contain the equivalent of approximately 7500 Gigatonnes (Gt) of $\mathrm{CO} 2$ - that is more carbon than is contained in all the remaining oil stocks on the planet and more than double the total amount of carbon currently in the atmosphere. However, when forests are destroyed or degraded by activities such as logging and conversion of forests to agricultural land, they release large quantities of $\mathrm{CO} 2$ and other GHGs, and become a significant (and, for some developing countries, a primary) source of GHG emissions and contributor to climate change.

\section{Deforestation And Climate Change}

India is a large developing country with nearly 700 million rural population directly depending on climate-sensitive sectors (agriculture, forests and fisheries) and natural resources (such as water, biodiversity, mangroves, coastal zones, grasslands) for their subsistence and livelihoods. Further, the adaptive capacity of dry land farmers, forest dwellers, fisher folk and nomadic shepherds is very low ${ }^{3}$. Climate change is likely to impact all the natural ecosystems as well as socio-economic systems as shown by the National Communications Report of India to the UNFCCC ${ }^{4}$. The key environmental challenges in India have been sharper in the past two decades.

One of the consequences of deforestation is that the carbon originally held in forests is released to the atmosphere, either immediately if the trees are burned, or more slowly as un-burned organic matter decays. Only a small fraction of the biomass initially held in a forest ends up stored in houses or other long-lasting structures. Most of the carbon is released to the atmosphere as carbon dioxide, but small amounts of methane and carbon monoxide may also be released with decomposition or burning. Cultivation also oxidizes $25-30 \%$ of the organic matter in the upper meter of soil and releases that to the atmosphere. Reforestation reverses these fluxes of carbon. While forests are re-growing, they withdraw carbon from the atmosphere and accumulate it again in trees and soil. Although deforestation, itself, may not release significant quantities of methane or nitrous oxide, these gases are often released as a consequence of using the cleared land for cattle or other ruminant livestock, paddy rice, or other crops, especially those fertilized with nitrogen.

Estimates on the contribution of deforestation to carbon emissions vary, but are commonly held to be around 19 per cent of global emissions greater than those emissions produced by the whole of the global transport sector. The bulk of emissions from deforestation arise when land is converted to agricultural production, particularly if forests are first cleared with burning. The potential for forests to become even greater sources of carbon emissions due to deforestation and degradation is massive. Deforestation is continuing at an alarming rate. Once distributed over half the planet, forests now cover only a quarter of its land surface and forest loss, particularly in the tropics, is continuing at an alarming rate. Beyond the tropics, there has been a significant loss of old-growth forests and the replacement of natural forests and woodlands with single-species plantations that provide few of the environmental, ecological and social benefits of native forests. While afforestation and reforestation are important, and helpful for supporting reduced emissions in many places, stopping deforestation is more urgent from a climate perspective. It takes decades for sapling to grow and absorb the amount of carbon that is released when a mature tree decays.

\section{International Collaboration And Efforts}

Admitting the well-founded concerns on the need to redress environmental problems, there were global calls for cooperation, action, and innovation. World leaders continued to engage and deliberate in international forums dedicated to climate and environment and also in forums, where sustainable development and climate change were an integral part of the discussions. Ambition or goal setting to reach targets, provision of finance and technology for developing countries, and institutions and mechanisms for capacity building were the common threads of negotiations running through all these forums. Among the others, few important ones are:

\section{Rio Declaration 1992}

In the 1980s, the scientific evidence linking GHG emissions from human activities with the risk of global climate change started to arouse public concern. The United Nations General Assembly responded in 1990 by establishing the Intergovernmental Negotiating Committee for Framework Convention on Climate

\footnotetext{
${ }^{2}$ Shue, H., 1999: Global environment and international inequality. Int. Aff., 75, 531-545.

3 Pielke, R.A., 1998, "Rethinking the role of adaptation in climate policy", Global Environmental Change, Vol 8, pages: 159-170.

${ }^{4}$ India's Initial National Communications to the United Nations Framework Convention on Climate Change, Ministry of Environment and Forests, New Delhi, 2004.
} 
Change. The UNFCCC (United Nations Framework Convention on Climate Change) held in 1992 at Rio de Janeiro adopted the framework for addressing climate change concerns. Internationally the UNFCCC (Convention) was set up in 1992 and entered into force in 1994. This was a crucial step towards putting in place the institutions and processes for the world's governments to take coordinated and effective action. As on date, 195 countries are Parties to the Convention. The ultimate objective of the Convention is to stabilize the concentrations of GHGs in the atmosphere at a level that would prevent dangerous anthropogenic interference with the climate system. Although global in scope, it differentiated the commitments/responsibilities of Parties on the basis of their respective capabilities, economic structures, resource capacities and on the basis of the principle of 'equity' which is at the core of the climate change debate. Hence, any discussion on stabilization of the concentrations of GHGs in the atmosphere should be preceded by a paradigm for equitable access to global atmospheric resources that determines the development space of nations.

The Convention lays down legally binding commitments for the developed countries, taking into account their historical responsibilities. The UNFCCC highlights two fundamental response strategies: mitigation and adaptation. While mitigation seeks to limit climate change by reducing the emissions of GHG (greenhouse gases) and by enhancing 'sink' opportunities, adaptation aims to alleviate the adverse impacts through a wide-range of system-specific actions. Albeit both mitigation and adaptation measures must be pursued to tackle the climate change problem and to create an effective and inclusive international climate change regime, more attention has been devoted to mitigation in the past, both in scientific research and policy debate. Sensitivity to the issue of adaptation has grown over the last couple of years, particularly after the IPCC (Intergovernmental Panel on Climate Change) TAR (Third Assessment Report). Adaptation has now emerged as an urgent policy priority, prompting action both within and outside the climate change negotiations. These commitments are to be implemented in the form of reduction of GHG emissions by the developed countries with reference to 1990 levels and provision of support to developing countries in terms of finance and technology so as to enable them to take voluntary mitigation and adaption measures. Such a level should be achieved within a time frame, sufficient to allow ecosystems to adapt naturally to climate change, to ensure that food production is not threatened and to enable economic development in a sustainable manner's. Acknowledging the global nature of climate change, the Climate Convention calls for the widest possible cooperation by all countries and their participation in an effective and appropriate international response, in accordance with 'their common but differentiated responsibilities and respective capabilities and their social and economic conditions'.

\section{Convention On Biological Diversity}

Global concerns about biodiversity found expression in the CBD adopted in 1992. The objectives of the Convention are: conservation of biodiversity, sustainable use of its components, and the fair and equitable sharing of benefits arising from the use of genetic resources. The Convention has near universal membership with 193 countries. The USA is the only major country that is not a Party. Following the ratification of the CBD, India also enacted the Biological Diversity Act in 2002 and notified the Rules in 2004 to give effect to the provisions of the CBD.

\section{Kyoto Protocol (1997)}

The UN Conference of Parties held in Kyoto in 1997 adopted the Kyoto Protocol as the first step towards addressing climate change. The Protocol shares the Convention's objective, principles and institutions, but significantly strengthens the Convention by committing Annex I Parties ${ }^{6}$ to individual, legally-binding targets to limit or reduce their GHG emissions. To achieve the goals of the Climate Convention, the Kyoto Protocol broke new ground by defining three innovative 'flexibility mechanisms' to lower the overall costs of achieving its emissions targets. These mechanisms enable Parties to access cost-effective opportunities to reduce emissions or to remove carbon from the atmosphere in other countries. While the cost of limiting emissions varies considerably from region to region, the benefit for the atmosphere is the same, wherever the action is taken. Much of the negotiations on the mechanisms have been concerned with ensuring their integrity. The three Kyoto mechanisms are as follows:

Joint Implementation (JI): Under Article 6 provides - to implement projects that reduce emissions, or remove carbon from the atmosphere, $\mathrm{s}$, in return for emission reduction units (ERUs).

Clean Development Mechanism (CDM): Defined in Article 12 provides for Annex I Parties to implement projects that reduce emissions in non-Annex I Parties ${ }^{7}$, or absorb carbon through afforestation or reforestation

\footnotetext{
${ }^{5}$ United Nations Framework Convention on Climate Change 1992 (UNFCCC), Geneva, Switzerland, United Nations Environment Program Information Unit on Climate Change, 1992.

${ }^{6}$ Annex I Parties means industrialized countries that have committed themselves to reducing GHG emissions

${ }^{7}$ Non-Annex I Parties are developing countries as well as Least Developing Countries (LDCs) which do not have any obligation to reduce emissions
} 
activities, in return for certified emission reductions (CERs) and assist the host Parties in achieving sustainable development and contributing to the ultimate objective of the Convention.

Emissions Trading (ET): As set out in Article 17, provides for Annex I Parties to acquire certified emission reduction units from other Annex I Parties.

Among the above three mechanisms, only CDM is relevant to developing countries such as India. Developing countries could view CDM as an opportunity not only to attract investment capital and Environmentally Sustainable Technologies (ESTs) but also to implement innovative technical, institutional and financial interventions to promote energy efficiency, renewable energy and forestry activities that contribute to sustainable development. Projects specially designed and implemented in developing countries under CDM, leading to carbon emission reduction or sequestration will receive payments from institutions and agencies ${ }^{8}$.

\section{The Kyoto Protocol And Developing Countries}

The idea of "compensated reduction" i.e., tropical countries might reduce national deforestation under an historical baseline and be allowed internationally tradable carbon offsets having demonstrated reductions emerged out the polemical debates surrounding forests between the approval of Kyoto and the Marrakech accords. All perspectives in this debate have contributed to considerable growth and development in our understanding and analysis of forest climate relationships and most particularly the diverse list of distinguished international scientists and experts who contributed to it attests. There is now broad consensus on some previously contentious or unclear issues. The importance of addressing emissions from tropical deforestation, as distinct from the sequestration of carbon in "sinks", is widely accepted. Scientists, policy makers and environmentalists agree that reducing tropical deforestation is a critical piece of any international emissions reduction regime, in particular if atmospheric concentrations of $\mathrm{CO}_{2}$ are to remain below the often-cited figure of $450 \mathrm{ppm}$. There is broad agreement that tropical nations need some form of economic incentive to reduce deforestation, and that developed countries should compensate countries that control deforestation.

Much of the controversy around forests and sinks since Kyoto arose from the fact that quantitative reduction targets were negotiated in Kyoto before reaching agreement on the means through which targets could be met. Thus, including sinks and agricultural lands meant in effect reducing the targets already negotiated. Addressing tropical deforestation in the context of post-2012 emissions reduction targets would, to the contrary, add to overall emissions reductions and benefit the atmosphere.

It is highly likely that allowing reduced deforestation into the carbon market would produce modest, although not insignificant, amounts of offsets initially. Quantities allowed to trade could be limited through negotiation. Even if not formally limited, deforestation offsets will not flood the market and depress carbon prices. For several reasons, any effective compensated reductions program must at the outset necessarily be a national program. Allowing companies or individuals with high historic deforestation to enter markets directly would reward past deforestation but not conservation and thus create perverse incentives. Furthermore, in all remaining large tropical forest frontiers, or potential future frontiers, governments will need to make substantial, and long-term, investments in governance structure (monitoring and enforcement capacity, organization of land tenure, allocation of property rights) before carbon offsets can become an economic alternative for individuals or companies. Neither forest protection nor equitable allocation of carbon rights will happen in unregulated open access frontiers.. Compensated reductions would first of all help governments halt or restrain wasteful, unproductive, or low-value deforestation, and support conservation. Only in a later stage will it be possible to determine to what extent carbon might be an attractive economic alternative for individuals or companies in tropical forests. Further, since reductions must refer to a national baseline, only nations can seek compensation for them. No nation can be obliged to sell more offsets than it finds advantageous, thus, flooding the market and driving down prices is unlikely. The prospect of deforestation-based carbon offsets has raised concerns about the permanence of deforestation reductions.

Protecting forests will preserve these other climate-stabilizing interactions as well as slowing clear cutting and fires. Several crediting and accounting proposals discussed in this volume address the permanence issue. Ultimately, however, the risks of using reduced deforestation for carbon offsets must be weighed against the cost of doing nothing or of hoping that official assistance programs that have never approached the scale needed to affect deforestation rates will suddenly increase by orders of magnitude. Nothing could do more to preserve the biological diversity of the planet. More dangerous to the global climate system than any issues of leakage or permanence of offsets for reduced deforestation, is the prospect of failing to sustain an international system of mandatory emissions reductions and a flourishing market for ecosystem services and of failing to enlist a growing number of the world's nations in them. As a voluntary mechanism that offers substantial incentives for major developing countries to reduce emissions by means of their own choosing, compensated

\footnotetext{
${ }^{8}$ Ravindranath, N. H. and Sathaye, J., Climate Change and Developing Countries, Kluwer Academic Publishers, Dordrecht, Netherlands, 2002.
} 
reduction of deforestation suggests one way, among many that will be needed, to help avert the global climate crisis while time remains ${ }^{9}$.

Developing countries that elect to reduce their national emissions from deforestation during the 5 years of the first commitment period (taking average annual deforestation over some agreed period in the past, measured with robust satellite imagery techniques, as a baseline), would be authorized to issue carbon certificates, similar to the Certified Emissions Reductions (CERs) of the CDM, which could be sold to governments or private investors. Once having received compensation, countries would agree not to increase, or to further reduce, deforestation in future commitment periods (provided that Annex I countries fulfil their obligations). A country that committed to reducing deforestation and was compensated, but instead increased deforestation, would take the increment increased as a mandatory cap in the next commitment period.

\section{Reducing Deforestation}

Tropical country governments can reduce deforestation through adequate funding of programs designed to enforce environmental legislation, support for economic alternatives to extensive forest clearing (including carbon crediting), and building institutional capacity in remote forest regions. Moreover, substantial forest can be saved in protected areas if adequate funding is available. More developing countries will be likely to use these mechanisms if they have access to the financial resources necessary to pay for them. Countries that want advance financing for deforestation reduction could make agreements with bilateral or multilateral financial institutions, or attract private sector investments for this purpose. Public financing should not, however, be diverted from existing development assistance, as agreed in the Marrakech Accords. Countries might also issue discounted carbon bonds, redeemable in 2012, but conditioned on verification and certification of reductions. Compensated reductions differs from previous forest protection programs and agreements in that it promises to give governments, forest communities, and private owners access to a market for forest ecosystem services, creating the economic value for standing forest long understood as essential for large scale forest conservation.

Progress towards an effective emissions reductions regime will require unprecedented international consensus. Compensated reductions is a voluntary mechanism that offers tropical countries access to substantial market incentives for reducing emissions, while respecting their sovereignty in selecting means and investing returns. It is in essence a strategy for an equitable global distribution of the costs and allocation of benefits for reducing deforestation. It may thus allow negotiators to move beyond ineffective good intentions on one hand and unacceptable mandatory targets for developing countries on the other ${ }^{10}$.

\section{Conclusion}

To conclude, global deforestation and forest degradation rates have a significant impact on the accumulation of greenhouse gases (GHGs) in the atmosphere. The Food and Agriculture Organization estimated that during the 1990s 16.1 million hectares per year were affected by deforestation, most of them in the tropics. The Intergovernmental Panel on Climate Change (IPCC) calculated that, for the same period, the contribution of land-use changes to GHG accumulation into the atmosphere was $25 \%$ of the total annual global emissions of GHGs. The United Nations Framework Convention on Climate Change (UNFCCC), in recognising climate change as a serious threat, urged counties to take up measures to enhance and conserve ecosystems such as forests that act as reservoirs and sinks of GHGs. The Kyoto Protocol, adopted in 1997, complements the UNFCCC by providing an enforceable agreement with quantitative targets for reducing GHG emissions. For fulfilling their emission-limitation commitments, industrialized countries can use land-based activities, such as reducing deforestation, establishing new forests (afforestation and reforestation) and other vegetation types, managing agricultural and forestlands in a way that the 'carbon sink' is maximized.

The concept of "Compensated Reduction" offers a potentially crucial set of incentives for reducing greenhouse gas (GHG) emissions from tropical deforestation. It is urgent that these incentives begin to flow as soon as possible - urgent from the perspective of limiting emissions and stabilizing GHG concentrations at a level, and in a time frame, that would avert dangerous irreversible climate change. It is urgent from the perspective of saving the world's dwindling rainforest biodiversity. And it is urgent from the social perspective of the communities that live in and depend on the world's rainforests.

\footnotetext{
${ }^{9}$ http://www.merid.org/ /media/Files/Projects/Congo\%20Basin\%20Microsite/D\%C3\%A9claration\%20Bassin\% 20du\%20Congo.pdf

${ }^{10}$ Swaminathan, M.S., 2005: Environmental education for a sustainable future.Glimpses of theWork on Environment and Development in India, J.S. Singh and V.P. Sharma, Eds., Angkor Publishers, New Delhi, $51-71$.
} 